\title{
Organometallic iron complexes as potential cancer therapeutics
}

\author{
Gabriela Mojžišová1 ${ }^{凶}$, Ján Mojžiš² and Janka Vaškováa \\ 1Department of Experimental Medicine, Faculty of Medicine, P. J. Šafárik University, Košice, Slovak Republic; ${ }^{2}$ Department of Pharmacology, \\ Faculty of Medicine, P. J. Šafárik University, Košice, Slovak Republic; ${ }^{3}$ Department of Medical and Clinical Biochemistry and LABMED, Faculty of \\ Medicine, P. J. Šafárik University, Košice, Slovak Republic
}

\begin{abstract}
Metal-containing drugs have long been used for medicinal purposes in more or less empirical way. The potential of these anticancer agents has only been fully realised and explored since the discovery of the biological activity of cisplatin. Cisplatin and carboplatin have been two of the most successful anti-cancer agents ever developed, and are currently used to treat ovarian, lung and testicular cancers. They share certain side effects, so their clinical use is severely limited by dose-limiting toxicity. Inherent or acquired resistance is a second problem often associated with platinum-based drugs, with further limits of their clinical use. These problems have prompted chemists to employ different strategies in development of the new metal-based anticancer agents with different mechanisms of action. There are various metal complexes still under development and investigation for the future cancer treatment use. In the search for novel bio-organometallic molecules, iron containing anti-tumoral agents are enjoying an increasing interest and appear very promising as the potential drug candidates. Iron, as an essential cofactor in a number of enzymes and physiological processes, may be less toxic than non essential metals, such as platinum. Up to now, some of iron complexes have been tested as cytotoxic agents and found to be endowed with an antitumor activity in several in vitro tests (on cultured cancer cell lines) and few in vivo experiments (e. g. on Ehrlich's ascites carcinoma). Although the precise molecular mechanism is yet to be defined, a number of observations suggest that the reactive oxygen species can play important role in iron-induced cytotoxicty. This review covers some relevant examples of research on the novel iron complexes.
\end{abstract}

Key words: organometallic iron complexes, cytotoxic and antiproliferative effects, anticancer agents

Received: 18 February, 2014; revised: 26 October, 2014; accepted: 03 December, 2014; available on-line: 19 December, 2014

\section{INTRODUCTION}

After cardiovascular disease, cancer is the second most frequent cause of death in developed countries. Cancer continues to be a worldwide killer, despite the enormous amount of research and rapid developments seen during the past decade. Global cancer rates have been increasing primarily due to an aging population and lifestyle changes in the developing world (Jemal et al., 2011). The most significant risk factor for developing cancer is old age. Although it is possible for cancer to strike at any age, most people who are diagnosed with invasive cancer are over the age of 65 (Anisimov et al., 2009; Hajdu et al., 2011). By 2020, the world population is expected to have increased to 7.5 billion; of this number, approximately 15 million new cancer cases will be diagnosed, and 12 million cancer patients will die (Brayand \& Moller, 2006).

Many different substances have been tested in anticancer therapy. Only some of them are currently available to treat cancer and many more are being tested for their ability to destroy cancer cells (Desoize, 2004). Cytotoxic drugs used for the treatment of cancer today have the potential to be very harmful to the body unless they are very specific to cancer cells. Moreover, cancer cells have the propensity to become resistant to therapy, which is the major limitation of current therapeutic concepts (Gottesman, 2002). Therefore, novel therapeutic agents for cancer treatment are needed.

Although medicinal chemistry was almost exclusively based on organic compounds and natural products, metal complexes have gained a growing interest as pharmaceuticals for the use as diagnostic/chemotherapeutic agents (Rafique et al., 2010). There is no doubt that the discovery of cisplatin, represents one of the most significant events for cancer chemotherapy in the 20th century. Cisplatin is highly effective in treating a variety of cancers, especially ovarian, lung, head, and neck cancers, as well as testicular and bladder tumors (Galluzzi et al., 2012). Its effectiveness has been hampered by toxic side effects and tumor resistance that often leads to the occurrence of secondary malignancies (Chen et al., 2009). Unfortunately, cisplatin induces cumulative and dosedependent nephrotoxicity, which restricts the use of high doses to maximize the therapeutic efficacy (Marzano et al., 2009). The cisplatin-induced nephrotoxicity is likely caused by a combination of multiple mechanisms involving DNA damage, caspase activation mitochondrial dysfunction and formation of reactive oxygen species (Pan et al., 2009). In addition, cisplatin is not orally bioavailable, and both inherited and acquired resistance seriously limit its applications (Kelland, 2000).

These unresolved problems in platinum-based anticancer therapy have stimulated increased research efforts in the search for novel non platinum-containing metal species as cytostatic agents with different mechanisms of action, biodistribution and biological activity. A growing number of investigations demonstrate that the development of new metal agents with modes of action different from cisplatin is possible (Ott \& Gust, 2007).

e-mail: gabriela.mojzisova@upjs.sk

Abbreviations: ER+, positive estrogen receptor; ERa, estrogen receptor $a_{;}: I_{50}$ half maximal inhibitory concentration; $\mathrm{OH} \cdot$ radicals, hydroxyl radicals; RNS, reactive nitrogen species; ROS, reactive oxygen species; UV radiation, ultraviolet radiation 
The antitumor properties of a number of different metal ions and their complexes have been evaluated, but only a few non-platinum metal-based drugs are currently in clinical studies. Some of clinical studies may bring new candidates for modern chemotherapy in the next few years. The most promising ones contain ruthenium and gallium ions (Abu-Surrah \& Kettunen, 2006). The search for new effective drugs will remain of the highest priority in the field of cancer research. A major challenge is to design new drugs that will be more selective for cancer cells, and thus have lesser side effects (Jungwirth et al., 2011).

\section{IRON COMPLEXES AS POTENTIAL ANTI-CANCER COMPOUNDS}

As it was mentioned above, current research in the medical field is aimed at the design of new compounds which are active against a wider range of cancers, and have lesser side-effects.

The organometallic sandwich compound ferrocene is an interesting building block for the design of biologically active molecules because of its unique structure, its robustness in aqueous solutions, its favorable redox properties and low toxicity (Dombrowski et al., 1986; Meggers, 2007). It can be injected, inhaled, or taken orally without causing major health problems. The toxicity of ferrocene was also tested in beagle dogs that were fed up to $300 \mathrm{mg}^{\circ} \mathrm{kg}^{-1}$ per day for 6 months or even $1 \mathrm{~g} \times \mathrm{kg}^{-1}$ for up to 3 months with no signs of acute toxicity or even deaths (Yeary, 1969). Unsubstituted ferrocene itself is not active as it is not soluble in water. However, appropriately substituted active ferrocenes could interconvert inside the tumour cells between the oxidation state +2 (ferrocene) and the oxidation state +3 (ferrocenium ions). Simple ferrocenium salts were the first iron compounds for which an antiproliferative effect on cancer cells was demonstrated (Köpf-Maier et al., 1984). Although the precise mechanism of antiproliferative action is still uncertain, their potential to induce the formation of reactive oxygen species (ROS), e. g., $\mathrm{OH}^{*}$ radicals, which may react with DNA or other biomolecules is considered to be important in their mode of action (Ossela et al., 2000; Gasser et al., 2011; Acevedo-Morantes et al., 2012). Numerous ferrocene derivatives are among the most potential compounds which may be used in cancer research (Al-Bari et al., 2007).

Almost fourthy years ago, Fiorina and co-authors (1978) for the first time reported the anticancer activity of ferrocenyl compounds bearing amine or amide groups against lymphocytic leukemia. They found that some compounds exhibited low but significant antitumor activity.

Since then, several types of ferrocenyl compounds have been synthesized and tested for antiproliferative purposes.

Probably among all the ferrocene derivatives with anticancer properties, the ferrocifens are the most widely studied due to their potential to suppress breast cancer cells growth. Ferrocifens are the complexes of ferrocene with 4-hydroxytamoxifen, an active metabolite of tamoxifen. Tamoxifen is a selective estrogen receptor modulator prescribed for patients diagnosed with positive estrogen receptor $(\mathrm{ER}+)$ breast cancer. Jaouen and co-workers (2004) studied antiproliferative effect of hydroxyferrocifens on both, estrogen-dependent breast cancer cells (MCF-7) as well as hormone-independent breast cancer cells (MDA-MB-231). It was found that in MCF-7 cells, the effect of ferrocifens was slightly over the antiprolife- rative effect of hydroxytamoxifen at concentration $0.1 \mu \mathrm{M}$ and significantly superior to that of hydroxytamoxifen at $1 \mu \mathrm{M}$. It is believed that the activity of ferrocifens against estrogen-dependent cancer cell lines is related to the ability of hydroxytamoxifen competively to bind to the estrogen receptor $(E R \alpha)$ subtype, thus repressing estradiol-mediated DNA transcription in the tumor tissue. Impressive results have been obtained in MDA-MB-231 cells. In these cells hydroxytamoxifen has no effect, while ferrocifens significantly decreased MDA-MB-231 cells survival with $\mathrm{IC}_{50}=0.5 \mu \mathrm{M}$. This indicates a new and different mode of action for ferrocifens and it is suggested that the ferrocene group may modulate this effect. It may be intracellularly oxidized and the corresponding ferricinium cation may effect an intramolecular oxidation producing cytotoxic species such as quinone methides, which would be responsible for the antiproliferative activity (Hillard et al., 2005). Moreover, Lu and coworkers (Lu et al., 2014) documented that antiproliferative activity of ferrocifen can also be associated with an increased production of reactive oxygen/ nitrogen species (ROS/RNS). On the other hand, ROS production was not observed on melanoma cells, while ferrocifen also showed an antiproliferative effect on these cells. As authors suggested, melanocytes due to constant oxidative aggression induced by UV radiation might have developed specific metabolic pathways dedicated to the efficient scavenging of ROS, a necessary for their survival (Michard et al., 2008).

The success with ferrocene-tamoxifen complex prompted the next research in this field. Raloxifene is an another SERM that decreases breast cancer risk in postmenopausal women and may have the benefits of the widely used tamoxifen with fewer side effects. Fereira and coworkers (Fereira et al., 2009) replaced a phenyl ring on raloxifen by a ferrocenyl moiety and prepared several 2-benzoyl3-ferrocenylbenzo[b]thiophenes. All tested compounds showed considerable cytotoxic activity against different cancer cell lines. Among them [3-ferrocenyl-6-methoxybenzo[b] thiophen-2-yl][4-(piperazin-1-yl)methylphenyl]methanone was even more potent than the reference compound, cisplatin. Moreover, caspase-3 activation analyses revealed a caspase-3-dependent apoptotic cell-death mechanism.

Numerous other ferrocene derivatives have been tested for antiproliferative purposes. Among those, a ferrocene-acridine conjugate was found to be highly cytotoxic. The anticancer activity of acridines is mainly attributed to the planarity of these aromatic structures, which can intercalate within the double-stranded DNA structure, thus interfering with the cellular machinery (Belmont et al., 2007). In 1992 Ong and co-workers synthesized new ferrocene compound by fusion ferrocene with acridine (Ong et al., 1992). When compared its antiproliferative activity with the analogous ferrocenyl derivative lacking the acridine moiety they found that the new ferrocene-acridine was potent cytotoxic agent against four cell lines.

Some research groups tried to increase the anticancer properties of some nucleosides resp. nucleobases by attaching to ferrocene. Simenel and coworkers (Simenel et al., 2009) synthesized several complexes of ferrocenylalkyl with adenine, thymine, cytosine and 5-iodo-cytosine. They found strong antitumor effect $1 \mathrm{~N}$-ferrocenylmethyl thymine which suppressed tumor frequency by $70 \%$ in mice bearing adenocarcinoma 755 compared to control. Moreover, synergism of antitumor activity with the cyclophosphamide was also demonstrated.

Recently, the synthesis and properties of two chiral ferrocene derivatives containing a nucleobase and a hydroxyalkyl group were reported. The compounds show promising anticancer activity against five different cancer 
cell lines. As authors suggested, both functional groups are required for the optimal activity (Nguyen et al., 2014).

Prostate cancer is the second most frequently diagnosed cancer (at 15\% of all male cancers) and the sixth leading cause of cancer death in males worldwide (Jemal, 2011). Current treatments for these cancers include antihormone therapy in the early stages of disease, surgery, radiotherapy and chemotherapy but these frequently affect quality of life and have significant side effects. The promising strategy to create efficient drugs for hormonedependent prostate cancers is an idea of attaching ferrocene to androgens and antiandrogens.

Top and coworkers (Top et al., 2009) synthesized and studied biological activity of a series of organometallic complexes of the steroidal androgens testosterone and dihydrotestosterone substituted at the $\mathrm{C}-17$ position of the steroid skeleton with ferrocenyl. Among them two ferrocenyl derivatives of ethynyl testosterone showed a strong antiproliferative effect on the hormone-independent prostate cancer cells PC-3 with $\mathrm{IC}_{50}$ in the micromolar range.

The modification of the biological effects of some biologically active molecules by ferrocene is an active field of study and many other complexes were synthesized and studied for their biological activity including ferrocenylphenols (Hillard et al., 2007; Hamels et al., 2009), ferrocenyl-ampicillin and ferrocenyl-6-aminopenicillinic acid (Skiba et al., 2012) or ferrocenyl-flavonoids (Monserrat et al., 2013). Also, our preliminary results with ferrocenylchalcones confirmed antiproliferative potential of these compounds. We found significant supression of growth of several cancer cells (human acute T-lymphoblastic leukemia, cervical carcinoma, breast cancer and lung carcinoma) in the low-micromolar range. Moreover, we found that some steps of angiogenesis (endothelial cells migration and matrix metalloproteinase activity) were inhibited with the studied compounds (Mojzisova et al., 2014).

Another interesting approach for the development of anti-tumourally active iron species was taken by preparing iron carbonyl nucleosides, which were able to induce apoptotic effects.

Treatment of melanoma cells with the cytosine analogue ferropoptoside, which contains an iron carbonyl complex, resulted in strong induction of apoptosis. Surprisingly, caspases were not involved in the initial phase. On the other hand, production of ROS appeared as an early effect, and antioxidant vitamin E completely prevented induction of apoptosis (Franke et al., 2010). Recently, it was documented apoptosis-inducing properties of iron-containing nucleoside analogues containing a butadiene $\mathrm{Fe}(\mathrm{CO})_{3}$ substructure in Burkitt-like lymphoma cells. The highest cytotoxicity was also observed in compounds with cytosine as a nucleobase. However, in contrast to above mentioned results, activation of caspase-3 was observed (Hirschhäuser et al., 2013).

Apoptosis-inducing effects could also be noted with other iron species. For example, iron (II) complexes containing pentadentate pyridyl ligands displayed high cytotoxic activities and induced apoptosis (Wong et al., 2005).

It has been shown that the nontoxic ferric-sorbitol-citrate complex (FSCC) inhibited the proliferation of malignant cells, but did not appreciably alter proliferation of normal cells. An increased number of cells in G1 and early $\mathrm{S}$ phase suggested that iron excess blocked the cell cycle before the onset of DNA synthesis. Since FSCC could block DNA synthesis and probably can induce oxidative stress in cells, the question then arises as to which type of mechanism is responsible for this anticancer action. As authors suggested, free radicals damage cellular lipid membranes, proteins, DNA and may induce cell death by apoptosis or other forms of cell death. (Flajsig \& Poljak-Blazi, 1990; Poljak-Blazi et al., 2000).

The aim of the Zhivkova et al., (2010) study was to evaluate the effect of two newly synthesized Fe mixed ligand complexes on viability and proliferation of cultured tumor cells. Among the cell lines used as experimental models in their investigations, the chicken hepatoma cells were found to be the most sensitive to the cytotoxic and antiproliferative effects of the tested compounds.

Woldemariam and Mandal (Woldemariam \& Mandal, 2008) synthesized a water soluble Fe(III)-salen complex and investigated its biochemical effects on DNA in vitro and on cultured human cells. They showed that it produces free radicals and induces DNA damage. Interestingly, upon treatment with $\mathrm{Fe}(\mathrm{III})$-salen at concentration as low as 10 $\mu \mathrm{M}$, human cells showed morphological changes, nuclear fragmentation, and nuclear condensation that are typical features of apoptotic cell death. Furthermore, treatment with $\mathrm{Fe}(\mathrm{III})$-salen resulted in translocation of cytochrome $c$ from mitochondria to cytosol affecting mitochondrial membrane permeability. Their results demonstrated that Fe(III)-salen not only damages DNA in vitro, but also induces apoptosis in human cells via mitochondrial pathway. Iron (III)-salophene with selective cytotoxic and antiproliferative properties have also been used in platinum resistant ovarian cancer cells (Rafique et al., 2010).

At present, research is going on to design new compounds which are active against a wide range of cancers and have lesser side effects. Among the available strategies to design affordable and efficient drugs, the use of organometallics (Allardyce et al., 2005), and especially of ferrocene (Fouda et al., 2007), clearly offers new possibilities since these compounds may exhibit enhanced chemical and pharmacological properties compared to the purely organic parent drugs (Quirante et al., 2011).

\section{CONCLUSION}

Much work has been done on metals and metal compounds. A surprising number of drugs contain metals. Every year thousands of new metal compounds are prepared and identified by analysis and chararacterized by spectroscopia and other physical methods. Only some of them play a serious role in chemotherapy. Organometallic compounds of iron constitute a very large group of substances, which in recent years has attracted considerable attention. Although iron has a long history of medical application, coordination compounds of iron have been investigated as potential antiproliferative agents only in the last few decades, particularly after the discovery of cisplatin, the most widely used anticancer metallodrug. Iron, as an essential cofactor in a number of enzymes and physiological processes, may be less toxic than non essential metals, such as platinum. Up to now, a great variety of iron complexes have been tested as cytotoxic agents and found to be endowed with an antitumor activity in several in vitro tests and few in vivo experiments. Some of them e. g. ferrocene showed interesting and promising anti-tumor effects especially in in vitro experiments. On the other hand, knowledge of the exact mechanism of their potential antiproliferative and antiangiogenic mechanisms are still limited and therefore, requires more intensive pharmacological research.

\section{Acknowledgements}

This work was supported by the grant VEGA $1 / 0751 / 12$, VEGA $1 / 1236 / 12$ and partially supported 
by the Agency of the Slovak Ministry of Education for the Structural Funds of the EU, under project ITMS: 26220220104 (15\%), ITMS: 26220120058 (15\%) and ITMS: $26220220152(15 \%)$.

\section{REFERENCE}

Abu-Surrah AS, Kettunen M (2006) Platinum group antitumor chemistry: design and development of new anticancer drugs complementary to cisplatin. Curr Med Chem 13: 1337-1357.

Acevedo-Morantes CY, Meléndez E, Singh SP, Ramírez-Vick JE (2012) Cytotoxicity and reactive oxygen species generated by ferrocenium and ferrocene on MCF7 and MCF10A cell lines. J Cancer Sci Ther 4: 271-275.

Al-Bari MA, Hossen MF, Khan A, Islam MR, Kudrat-E-Zahan M, Mosaddik MA, Zakaria CM, Islam MA (2007) In vitro antimicrobial and cytotoxic activities of ferrocene derivative compounds. Pak J Biol Sci 10: 2423-2429.

Allardyce CS, Dorcier A, Scolaro C, Dyson PJ (2005) Development of organometallic (organo-transition metal) pharmaceuticals. Appl Organomet Chem 19: 1-10.

Anisimov VN, Sikora E, Pawelec G (2009) Relationships between cancer and aging: a multilevel approach. Biogerontology 10: 323-338.

Belmont P, Bosson J, Godet T, Tiano M (2007) Acridine and acridone derivatives, anticancer properties and synthetic methods: where are we now? Anticancer Agents Med Chem 7: 139-169.

Brayand F, Moller B (2006) Predicting the future burden of cancer. Nat Rev Cancer 6: 63-74.

Desoize B (2004) Metals and metal compounds in cancer treatment. Anticancer Res 24: 1529-1544.

Dombrowski KE, Baldwin W, Sheats JE (1986) Metallocenes in biochemistry, microbiology and medicine. J Organomet Chem 302: 281306.

Ferreira AP, da Silva JLF, Duarte MT, da Piedade MFM, Robalo MP, Harjivan SG, Marzano C, Gandin V, Marques MM (2009) Synthesis and characterization of new organometallic benzo[b]thiophene derivatives with potential antitumor properties. Organometallics 28: 5412-5423.

Fiorina VJ, Dubois RJ, Brynes S (1978) Ferrocenyl polyamines as agents for the chemoimmunotherapy of cancer. J Med Chem 21: 393-395.

Flajsig I, Poljak-Blazi M (1990) Influence of iron on proliferation and cell cycle kinetics on cultured malignant and nonmalignant cells. Oncology 47: 443-446.

Fouda MFR, Abd-Elzaher MM, Abdelsamaia RA, Labib AA (2007) On the medicinal chemistry of ferrocene. Appl Organomet Chem 21: 613-625.

Franke JC, Plötz M, Prokop A, Geilen CC, Schmalz HG, Eberle J (2010) New caspase-independent but ROS-dependent apoptosis pathways are targeted in melanoma cells by an iron-containing cytosine analogue. Biochem Pharmacol 79: 575-586.

Galluzzi L, Senovilla L, Vitale I, Michels J, Martins I, Kepp O, Castedo M, Kroemer G (2012) Molecular mechanisms of cisplatin resistance. Oncogene 31: 1869-1883.

Gasser G, Ott I, Metzler-Nolte N (2011) Organometallic anticancer compounds. J Med Chem 54: 3-25.

Gottesman MM (2002) Mechanisms of cancer drug resistance. Annu Rev Med 53: 615-627.

Hajdu SI, Thun MJ, Hannan LM, Jemal A (2011) A note from history: landmarks in history of cancer, part 1. Cancer 117: 1097-1102.

Hamels D, Dansette PM, Hillard EA, Top S, Vessières A, Herson P, Jaouen G, Mansuy D (2009) Ferrocenyl quinone methides as strong antiproliferative agents: formation by metabolic and chemical oxidation of ferrocenyl phenols. Angew Chem Int Ed Engl 48: 9124-9126.

Hillard E, Vessières A, Thouin L, Jaouen G, Amatore C (2005) Ferrocene-mediated proton-coupled electron transfer in a series of ferrocifen-type breast-cancer drug candidates. Angew Chem Int Ed Engl 45: 285-290.

Hillard EA, Pigeon P, Vessières A, Amatore C, Jaouen G (2007) The influence of phenolic hydroxy substitution on the electron transfer and anti-cancer properties of compounds based on the 2-ferrocenyl1-phenyl-but-1-ene motif. Dalton Trans 21: 5073-5081.

Hirschhäuser C, Velcicky J, Schlawe D, Hessler E, Majdalani A, Neudörfl JM, Prokop A, Wieder T, Schmalz HG (2013) Nucleoside analogues with a 1,3-diene- $\mathrm{Fe}(\mathrm{CO}) 3$ substructure: stereoselective synthesis, configurational assignment, and apoptosis-inducing activity. Chem Eur I 19: 13017-13029.

Chen D, Milacic V, Frezza M, Dou QP (2009) Metal complexes, their cellular targets and potential for cancer therapy. Curr Pharm Des 15: $777-791$.

Jaouen G, Top S, Vessières A, Leclercq G, McGlinchey MJ (2004) The first organometallic selective estrogen receptor modulators (SERMs) and their relevance to breast cancer. Curr Med Chem 11: 2505-2517.
Jemal A, Bray F, Center MM, Ferlay J, Ward E, Forman D (2011) Global cancer statistics. CA Cancer J Clin 61: 69-90.

Jungwirth U, Kowol CR, Keppler BK, Hartinger CG, Berger W, Heffeter P (2011) Anticancer activity of metal complexes: involvement of redox processes. Antioxid Redox Signal 15: 1085-1127.

Kelland LR (2000) Preclinical perspectives on platinum resistance. Drugs 59: 1-8.

Köpf-Maier P, Köpf H, Neuse EW (1984) Ferrocenium salts; the first antineoplastic iron compounds. Angew Chem Int Ed Engl 23: 456457.

Lu C, Heldt JM, Guille-Collignon M, Lemaître F, Jaouen G, Vessières A, Amatore C (2014) Quantitative analyses of ROS and RNS production in breast cancer cell lines incubated with ferrocifens. Chem Med Chem 9: 1286-1293.

Marzano C, Pellei M, Tisato F, Santini C (2009) Copper complexes as anticancer agents. Anticancer Agents Med Chem 9: 185-211.

Meggers E (2007) Exploring biologically relevant chemical space with metal complexes. Curr Opin Chem Biol 11: 287-292.

Michard Q, Jaouen G, Vessieres A, Bernard BA (2008) Evaluation of cytotoxic properties of organometallic ferrocifens on melanocytes, primary and metastatic melanoma cell lines. J Inorg Biochem 102: 1980-1985.

Mojzisova G, Mojzis J., Mirossay L, Vaskova J, Perjesi P, Bomba A (2014) Novel ferrocenyl chalcones as potential cancer therapeutics. Anticancer Res 34: 6065.

Monserrat JP, Tiwari KN, Quentin L, Pigeon P, Jaouen G, Vessières, A., Chabot GG, Hillard EA (2013) Ferrocenyl flavonoid-induced morphological modifications of endothelial cells and cytotoxicity against B16 murine melanoma cells. J Organomet Chem 734: 78-85.

Nguyen HV, Sallustrau A, Balzarini J, Bedford MR, Eden JC, Georgousi N, Hodges NJ, Kedge J, Mehellou Y, Tselepis C, Tucker JH (2014) Organometallic nucleoside analogues with ferrocenyl linker groups: synthesis and cancer cell line studies. $J$ Med Chem 57: 5817-5822.

Ong CW, Jeng JY, Juang SS, Chen CF (1992) A ferrocene-intercalator conjugate with a potent cytotoxicity. Bioorg Med Chem Lett 2: 929-932.

Osella D, Ferrali M, Zanello P, Laschi F, Fontani M, Nervi C, Cavigiolio $G$ (2000) On the mechanism of the antitumor activity of ferrocenium derivatives. Inorg Chim Acta 306: 42-48.

Ott I, Gust R (2007) Non platinum metal complexes as anti-cancer drugs. Arch Pharm Chem Life Sci 340: 117-126.

Pan H, Mukhopadhyay P, Rajesh M, Patel V, Mukhopadhyay B, Gao B, Haskó G, Pacher P (2009) Cannabidiol attenuates cisplatin-induced nephrotoxicity by decreasing oxidative/nitrosative stress, inflammation, and cell death. J Pharmacol Exp Ther 328: 708-714.

Poljak-Blazi M, Kralj M, Hadzija MP, Zarković N, Zarković K, Waeg $G$ (2000) Involvement of lipid peroxidation, oncogene expression and induction of apoptosis in the antitumorous activity of ferricsorbitol-citrate. Cancer Biother Radiopharm 15: 285-293.

Quirante J, Dubar F, González A, Lopez C, Cascante M, Cortés R, Forfar I, Pradines B, Biot C (2011) Ferrocene-indole hybrids for cancer and malaria therapy. J Organomet Chem 696: 1011-1017.

Rafique S, Idrees M, Nasim A, Kabar H, Athar A (2010) Transition metal complexes as potential therapeutic agents. Biotechnol Mol Biol Rev 5: 38-45.

Simenel AA, Morozova EA, Snegur LV, Zykova SI, Kachala VV, Ostrovskaya LA, Bluchterova NV, Fomina MM (2009) Simple route to ferrocenylalkyl nucleobases. Antitumor activity in vivo. Appl Organomet. Chem 23: 219-224.

Skiba J, Rajnisz A, de Oliveira KN, Ott I, Solecka J, Kowalski K (2012) Ferrocenyl bioconjugates of ampicillin and 6-aminopenicillinic acid - synthesis, electrochemistry and biological activity. Eur J Med Chem 57: 234-239.

Top S, Thibaudeau C, Vessieres A, Brule E, Le Bideau F, Joerger JM, Plamont MA, Samreth S, Edgar A, Marrot J, Herson P, Jaouen G (2009) Synthesis and structure activity relationship of organometallic steroidal androgen derivatives. Organometallics 28: 1414-1424.

Woldemariam GA, Mandal SS (2008) Iron(III)-salen damages DNA and induces apoptosis in human cell via mitochondrial pathway. $J$ Inorg Biochem 102: 740-747.

Wong ELM, Fang GS, Che CM, Zhu N (2005) Highly cytotoxic iron(II) complexes with pentadentate pyridyl ligands as a new class of anti-tumor agents. Chem Commun 36: 4578-4580.

Yeary RA (1969) Chronic toxicity of dicyclopentadienyliron (ferrocene) in dogs. Toxicol App Pharmacol 15: 666-676.

Zhivkova T, Kalfin R, Drakova L, Leventieva-Necheva E, Mosoarca EM, Tudore R, Costisor O, Alexandrova R (2010) Influence of newly synthesized mixed ligand iron complexes on viability and proliferation of tumor cells. Trakia J Sci 8: 73-77. 